Judge or Bureaucrat? How Administrative Law Judges Exercise Discretion in Welfare Bureaucracies

Author(s): Vicki Lens

Reviewed work(s):

Source: Social Service Review, Vol. 86, No. 2 (June 2012), pp. 269-293

Published by: The University of Chicago Press

Stable URL: http://www.jstor.org/stable/10.1086/666375

Accessed: 06/12/2012 20:42

Your use of the JSTOR archive indicates your acceptance of the Terms \& Conditions of Use, available at http://www.jstor.org/page/info/about/policies/terms.jsp

JSTOR is a not-for-profit service that helps scholars, researchers, and students discover, use, and build upon a wide range of content in a trusted digital archive. We use information technology and tools to increase productivity and facilitate new forms of scholarship. For more information about JSTOR, please contact support@jstor.org. 


\title{
Judge or Bureaucrat? How Administrative Law Judges Exercise Discretion in Welfare Bureaucracies
}

\author{
Vicki Lens \\ Columbia University
}

\begin{abstract}
Administrative law judges are neglected but powerful actors in public welfare bureaucracies, presiding over quasi-judicial hearings triggered if participants challenge a bureaucratic decision on public welfare benefits. Drawing on ethnographic observations of fair hearings, as well as interviews with administrative law judges and appellants, this study seeks to understand the ways in which these judges exercise discretion and how it affects the adjudication of disputes. Findings suggest that disputes generated by poorly run bureaucracies provide judges with limited opportunity to use professional skills or discretion to scrutinize bureaucratic practices. When opportunities for such judgments do arise, judges take widely divergent paths. Some align themselves with the welfare agency, enforcing bureaucratic practices rather than scrutinizing them. Others emphasize their neutrality and judicial role, scrutinizing and aligning agency practices with the law's underlying purposes.
\end{abstract}

The ability to adapt rules, and thereby to exercise discretion, is an entrenched feature of bureaucracies. Variously described as a boon and a blight, the exercise of discretion can make bureaucracies function better or worse. Workers can use discretion to individualize rules, finetuning their application so that general laws fit individual circumstances. Or workers can use discretion to "process rather than engage" clients, mechanizing the application of rules so that clients can be moved quickly through the system (Maynard-Moody and Musheno 2003, 12). How, why, and when workers in public welfare bureaucracies choose either of these routes is the subject of much scholarly inquiry (Lipsky 1980, 1984; Brodkin 1986, 1997; Handler 1986; Meyers, Glaser, and MacDonald 1998; Hasenfeld 2000; Sandfort 2000; Lurie 2006; Fording, Soss, and Schram 
2007). The literature focuses primarily on the least powerfully situated worker in the organizational hierarchy of welfare bureaucracies: the frontline worker. This study focuses instead on a more powerfully positioned and neglected bureaucratic actor: the administrative law judge.

Administrative law judges preside over quasi-judicial hearings that are triggered if participants challenge a denial, discontinuance, or reduction in public welfare benefits. Hearings are deployed only if a citizen formally challenges the state, and judges have the power to reverse frontline decisions. The style of decision making differs from that employed by workers on the front lines. Frontline decision making is hierarchical. It focuses on processing information accurately, efficiently, and consistently (Mashaw 1983; Adler 2003, 2006). In contrast, administrative law judges have the autonomy, professional knowledge, and skills to make individualized and complex determinations (Simon 1983). But as their title implies, administrative law judges are also bureaucratic actors, steeped in the language and lore of the bureaucracy. They possess a vast knowledge of its norms and expectations.

By drawing on ethnographic observations of fair hearings, as well as on interviews with administrative law judges and appellants, this study seeks to understand how administrative law judges exercise the discretion granted them by their professional training and their role in the bureaucracy. It investigates how they navigate the tension caused by their multiple roles. The study adds to understanding not only of this particular bureaucratic actor but also of the different ways that skilled, professional workers use discretion in public welfare bureaucracies.

\section{Context and Background}

The predominant view of welfare bureaucracies is that they are an institutional site whose power is steady, controlling, and often oppressive toward assertions of individual rights or preferences. As Joel Handler (1986) explains, welfare bureaucracies are sites of both social control and social help. Although they provide life-sustaining benefits, they also "regulate, exclude, and punish deviant behavior" (Handler 1996, 124). The work they do, Yeheskel Hasenfeld argues (2000, 329), is "moral work." It involves sorting people to distinguish the supposedly deserving from those deemed undeserving. This sorting typically takes the organizational form of bureaucratic processing. Unlike professional treatment, which is individualized and participatory, bureaucratic processing is often characterized by a rote and mechanical application of the rules by low-skilled frontline workers (Simon 1983). Discretion is channeled by organizational incentives. These incentives encourage workers to standardize assistance and use service options that fit the needs of the agency rather than those of the individual (Brodkin 1997). Workers exercise their discretion negatively, choosing to apply rules narrowly 
and overriding participants' "substantive status or individual preference" (Brodkin and Majmundar 2010, 828). Eligible participants may be wrongfully denied benefits because of the high barriers to claiming them (Brodkin and Majmundar 2010).

Designed to correct such errors, the fair-hearing system provides a forum for resolving disputes between frontline workers and citizens. As noted above, the method of decision making in hearings differs from that on the front lines. A form of bureaucratic legalism predominates there; guided by the principles of accuracy, efficiency, and uniformity, nonprofessional bureaucrats closely apply detailed rules (Mashaw 1983; Adler 2010; Kagan 2010). In contrast, hearings employ a form of adversarial legalism. Guided by individualized justice, not bureaucratic uniformity and efficiency, highly trained and skilled professionals weigh conflicting interpretations of laws and facts (Mashaw 1983; Adler 2010). The difference between the two settings is perhaps best captured in their clashing views on the use of discretion. Frontline discretion is primarily considered something to be tamed and curtailed, but judges are expected to exercise discretion; it is the hallmark of their professional role.

Judges, however, are also bureaucratic actors. In over half of the states they are part of the state welfare bureaucracy that has regulatory and supervisory oversight of local welfare agencies (Brodoff 2008). ${ }^{1}$ Unlike more formal judicial systems, the administrative hearing system imposes no clear dividing lines to distinguish the roles of the respective government officials. Judges and bureaucrats are part of the same welfare apparatus, although they have different roles. Through their daily interactions with bureaucratic officials, judges may be "'captured' by the agency" (Bernard 2003, 17). Judges also are limited to reviewing the disputes before them. These are shaped and defined by bureaucratic practices below. Thus, although hearings are organizationally separate from the front lines and the everyday workings of the bureaucracy, there is potential for seepage between the two; judges may use their discretion to replicate the norms and expectations of bureaucratic decision making, failing to check its worst excesses. The current study refers to this as the "bureaucratic approach." Or judges may reinforce their designated role as adjudicators of disputes and may safeguard against arbitrary state action. The study calls this the "adjudicator approach."

This study addresses several questions. What types of disputes are appealed? How do the nature and quality of these disputes affect the adjudication process? How do judges with bureaucratic and adjudicator approaches, respectively, exercise discretion in executing the key tasks

1. In the state where the study was conducted, local agencies (some operated by cities, others by counties, depending on the locale) administer the program and make the initial determination of benefits. The state agency has supervisory responsibility and also operates the fair-hearing system. 
of judging? How do these different approaches affect the adjudication of disputes?

\section{Methodology}

This study draws on data from two different fair-hearing units located in a state in the northeastern United States. One unit is located in a suburban area, and the other is in an urban area. The data are the result of a focused ethnography, a type of sociological ethnography that examines specific and well-defined interactions, acts, or social situations in the field rather than an entire system or culture (Knoblauch 2005). Focused ethnography is characterized by relatively short-term field visits and intensive data collection. Much of the data come from recordings, as well as field notes. They allow the researcher verbatim and oral access to naturally occurring talk in a social interaction. Focused ethnography is especially suited to the observation of hearing interactions, which are episodically structured exchanges bounded in space and time.

The two fair-hearing units in this study are part of the same state welfare bureaucracy. They thus are governed by the same rules and procedures but differ in size and complexity. The urban fair-hearing unit hears over 76,000 cases a year and represents a very large and complex organization involved in the mass processing of cases. The suburban unit hears less than a thousand and is representative of a smaller and less complex bureaucracy. The inclusion of both units allows this study to distinguish the features and characteristics common to the adjudication process from those related to the demands of each bureaucratic setting.

I conducted observations of 70 hearings presided over by seven judges in the suburban unit and 129 hearings presided over by 10 judges in the urban unit. The observations in the suburban unit took place for a total of 4 months during 2007 and 2008. The observations in the urban unit took place over a 3-month period in 2009. I conducted all hearing observations. I did not use a formal selection process in deciding which suburban unit hearings to observe. On days when there was a single calendar (i.e., a single judge conducted all hearings), I observed hearings in the order in which they occurred. On days when there were two calendars in that unit, I chose hearings on the basis of which appellant appeared first and was ready to proceed. In the urban unit, approximately 35 judges hear cases on any given day, and calendars are assigned by subject matter (e.g., for hearings related to food stamps, general public assistance, and medical programs). I did not choose the hearings observed in the urban unit but was assigned by the unit's supervising judge to observe a particular judge. Assignments were based on a combination of factors, including the hearing judge's availability and willingness to participate, as well as the nature of the cases he or 
she would preside over on the observation day. I commonly requested assignment to hearings that involved public assistance cases rather than hearings on food stamp cases. In between hearings, I also spoke with the judges.

During the hearings, I maintained a detailed log, recording both what was said (as much as I was able to record) and other observations. These other observations include physical descriptions of the parties and the environment of the room; obvious states of emotions (e.g., anger, crying, laughter); the parties' demeanor, tone, and style (e.g., authoritarian, conciliatory, antagonistic); the level of formality (e.g., how strictly or loosely procedural rules on evidence and testimony were followed); and quality of personal interactions (e.g., friendly, hostile, apathetic). I also recorded routine and standardized data for each hearing observation. These include the parties present, the issue that prompted the hearing, and the length of the hearing. I transferred field jottings and observations into full field notes immediately after actual observations. I used in-process memos to "identify and develop analytic themes" (Emerson, Fretz, and Shaw 1995, 100). The state agency responsible for conducting the hearings also provided an audio recording of each urban-unit hearing I observed. I had these recordings transcribed.

I conducted formal in-depth interviews with five judges in the suburban unit and five judges in the urban unit. I used a semistructured interview guide consisting of open-ended questions on their initial training and experience, their approach to conducting hearings, their perception of participants and the hearing process, and their decisionmaking processes. The interviews lasted between 1 and 21/2 hours. Because I was not granted permission to tape-record these interviews, I only took notes. To ensure the accuracy of the notes, I sent each interviewed judge a copy of the composed notes from our interview and asked him or her to check the contents for accuracy. Seven of the 10 judges responded to this request, providing corrections and edits.

Nine appellants from the suburban unit and 21 appellants from the urban unit were interviewed by a research assistant. If I were able to do so, I approached appellants after their hearing, giving them a flyer on the study, inviting them to participate in an interview at a later date, and requesting their phone number so they could be contacted for a follow-up interview. The 30 interviewed appellants responded to the flyer or phone calls and represent at least one appellant from 12 of the 17 judges observed. I used these interviews as a way to triangulate the data from hearing observations. Because the interview data come from a different collection method (interviews) and a different data source (appellants), they provide a more comprehensive understanding of the data than could be obtained from observation notes alone (Creswell 2007). The semistructured interview consisted of open-ended questions about the interviewees' reason for appealing and their experience at 
their hearing. It solicited their perceptions of the judge and the agency representative. It also asked them to characterize the treatment they received and perceptions concerning their ability to present their case. The interviews were recorded and transcribed verbatim.

The unit of analysis for this study is the case, which consists primarily of the hearing I observed. The focus is on the conversations and interactions that took place in the hearing room, not on the outcome of the hearing (i.e., who won or lost) or the soundness of the legal positions held by the parties (the appellant and the agency). ${ }^{2}$ Rather, the study focuses on how the appellant's case was presented, discussed, and shaped by the parties through the course of the hearing. I use my informal conversations with the judges in between cases (these were sometimes but not always about the individual cases I observed) and the subsequent interviews with the appellants to confirm my observations. These interactions are also used to further explore the parties' perceptions and experiences of the hearing process.

Data analysis began with a review of the field notes and transcripts. In the first reading, I identified major themes and noted them in the margins of the pages. I then used HyperRESEARCH, a computer software program designed for the analysis of qualitative data, to code my field notes and transcripts. Using grounded theory conventions, I began analysis by conducting line-by-line open coding; I attached descriptive codes to lines of data and identified similarities or variations in the text (Charmaz 2006). Next, I conducted focused coding, which involves identifying the most noteworthy and frequent line-by-line codes. I also attempted to choose codes that best categorize the salient dimensions of the emerging themes and patterns (Charmaz 2006). I then conducted axial coding, which builds codes into categories, defines the properties and dimensions of each category, and draws contrasts (Charmaz 2006). In the final step, all codes are integrated through a theoretical coding process that identifies the central themes in the findings (Charmaz 2006). Coding was an iterative process; I returned to previously coded transcripts and field notes to confirm, refute, or modify codes as they developed. I used analytical memos throughout the process. First, I employed them to define and describe various codes. I then used them

2. A particular outcome may be related to the thoroughness and fairness of the process and procedures used during hearings. It also may stem from the provisions of law and from the relative strengths and weaknesses of the parties' cases. Thus, even a model hearing, in which appellants have a full and fair opportunity to present their case, can result in negative outcomes for appellants. Because outcomes are such an imprecise measure of the quality of the process, they are not included in this study. Also, research firmly establishes the importance of procedural justice; people care about winning or losing but care even more about the fairness of the procedures. The components of procedural justice include voice, neutrality, respectful treatment, and trustworthiness (Casper, Tyler, and Fisher 1988; Sunshine and Tyler 2003; Tyler 2006). Thus, the study of process is valuable in its own right. 
to rebuild the coded data and establish a conceptual framework by exploring categories' relationships with subcategories (Charmaz 2006).

An example may be useful. In developing the category of judges whose approach I characterize as bureaucratic, I began with such first-level and focused codes as "blaming the appellant," "joining," "shifting the focus," and "narrowing the issues." I use the code "blaming the appellant" to identify situations in which the agency or judge highlights the appellant's mistakes or negligence, poses questions that assume the appellant is at fault, or asks questions that are not stated neutrally. I assign the code "joining" to situations in which the agency and judge act as one front, joining together during the hearing to interrogate the appellant. I employ the code "shifting the focus" to indicate that the agency or the judge shifts the focus away from the agency and onto the appellant. The code "narrowing the issues" describes instances in which the judge narrowed the issues and emphasized process over substance. I used these codes and others to develop the axial category "bureaucratic judging." I defined the dimensions and properties of the category through analytic memos. The category describes judges who rely on a form of excessive proceduralism, both in defining the issues in dispute and determining what evidence to accept. Theoretical coding occurred when I used this category and contrasted it with the one for judges who employed an adjudicatory approach (described below). I employ the two categories to describe the defining and contrary ways in which judges use discretion during hearings.

\section{Findings}

\section{Nature and Quality of Disputes}

Fair hearings are triggered by individuals who receive benefits through the welfare agency. They usually arise as an appeal of a formal notice in which the agency advises the recipient that his or her benefits are being denied, discontinued, or reduced. Appellants can also request a hearing without such a notice if they think that the agency made an error; however, the vast majority of appeals are triggered by a formal notice. The state in this study classifies issues into two main categories: eligibility issues and those related to work activities. Eligibility issues can arise if there are questions about whether the appellant established his or her eligibility for assistance. Issues related to work activities can arise if there are questions about whether the appellant complied with rules that condition receipt of assistance on engagement in work activities or whether the recipient is exempt from those rules. ${ }^{3}$

3. Federal and state law requires public assistance recipients in the subject county and city to engage in such work activities as attending assessment appointments, searching for a job, and working in subsidized or unsubsidized employment or work-experience pro- 
Disputes arising from eligibility and work-rules issues can be substantive or procedural. There are substantive eligibility rules concerning income and resource limits. Procedural rules specify steps for proving eligibility. These steps include the submission of specified documents and mandated face-to-face appointments (commonly called recertification). Likewise, compliance with the work rules involves a mix of substantive and procedural activities for both participants and welfare workers. Workers' substantive tasks include establishing and evaluating recipients' ability to engage in work activities or their reasons for not attending a specific work-related appointment or activity. One of the agency's procedural tasks involves informing participants of the date and place of mandated work activities. It also is charged with monitoring participants' attendance. For the participants, procedural obligations include notifying the agency if they cannot attend a mandated appointment and providing documentation of the reasons.

Whether a fair hearing arises from a dispute about process or substance is in part determined by organizational practices and procedures. Welfare bureaucracies often engage in excess proceduralism, requiring an abundance of documents and verification procedures. As a consequence, cases that make their way into the fair-hearing system often reflect this emphasis on procedural compliance. As will be more fully explained in the next section, some judges reinforce this emphasis, narrowly defining the scope of disputes to focus on the appellant's procedural noncompliance. However, the agency's compliance with procedural rules can also be the focus of a dispute. Especially in very large and complex bureaucracies, the need to process a massive number of cases can exacerbate the worst excesses of such proceduralism by generating an avalanche of processing mistakes. This, in turn, can shift the focus of fair hearings from the appellant's procedural noncompliance to the agency's, consequently altering the ways in which judges exercise their discretion.

The contrast between the urban and suburban units illustrates this dynamic. The urban welfare agency handles approximately 186,000 cases a year; the suburban agency handles about 11,000. Although the size of a bureaucracy does not necessarily and inevitably determine its propensity for making mistakes, many of the cases in the urban unit are riddled with the types of procedural errors that can emanate from the mass processing of cases. Notices are incomplete or incorrect. They miss or misstate essential and required information (e.g., the date of a mandated appointment). Because of incorrect computer inputs or a failure to update information, notices are also sent to the wrong addresses.

grams. Failure to comply with the work rules results in the imposition of a sanction, which is a pro rata reduction of the violator's portion of the grant. Sanctions can be appealed through the fair-hearing process. Recipients also may appeal determinations as to whether disability or other factors make them eligible for exemptions from the work rules. 
Case files lack essential documents, such as proof that the agency sent the appellant a letter advising him or her of an appointment. At other times, the case records contradict the notices sent to appellants (e.g., the file and notice record different dates for an alleged missed appointment). In the urban unit, both judges and agency representatives routinely anticipate and acknowledge the ubiquity of such errors. As one agency representative drily observed when confronted with yet another defective notice, "Surprise, surprise, this one is less than perfect." Cases in the suburban unit have fewer such defects and are more likely to proceed to a full hearing on the substance of the dispute.

As a consequence of the norms in the urban unit, judges there have less opportunity than their suburban counterparts to use their professional skills and discretion. Cases with procedural irregularities are easily and quickly resolved; according to the state agency, the agency withdraws its notice of discontinuance of welfare benefits in nearly 60 percent of all urban unit cases, obviating the need for a full hearing. ${ }^{4}$ Judges may choose to ignore the agency's procedural breaches and proceed to the merits of cases, but they rarely do so because the errors are ubiquitous and obvious. Also, legal principles emphasize due process and the adherence to procedural rules. ${ }^{5}$ As a practical matter, agency withdrawals also provide judges with a quick shortcut for resolving disputes because they eliminate the need for a full hearing and a decision on the merits. Thus, judges in both the bureaucratic and adjudicator categories routinely accept and encourage agency offers to withdraw defective notices of benefit discontinuance. Even after the agency withdraws the discontinuance notice, disputes persist over substantive issues. For example, the agency may withdraw the discontinuance notice because it did not correctly identify the date on which the recipient missed a mandated work appointment. However, an error in the discontinuance notice does not necessarily mean that the appellant did not miss the scheduled appointment. The urban unit differs from the suburban counterpart in that most suburban cases are ready to be adjudicated at the scheduled hearing; the procedural errors committed by the agency prevent substantive disputes concerning the work rules from surfacing at hearings. Reflecting on his role in such cases, one judge observed that hearings are "band-aids. You are just slapping a band-aid on the problem. You can't solve all the problems."

In sum, bureaucratic practices below shape the nature and quality of

4. In contrast, the withdrawal rate in the suburban unit is only 14 percent.

5. Due process is a principle embedded in the US Constitution; the Fourteenth Amendment prohibits the deprivation of property without due process of law. Its application to welfare benefits was established by the US Supreme Court in the landmark case Goldberg v. Kelly (397 U.S. 254 [1970]). The court held that the due process clause requires pretermination hearings before welfare benefits are discontinued or reduced. A central component of due process is that adequate notice be provided before a negative action is taken; thus, the defective notices described herein constitute a breach of this requirement. 
the disputes that make their way into the fair-hearing system above. The disputes generated by a poorly run bureaucracy are different, both qualitatively and quantitatively, than disputes generated by one that is run more effectively. The influence of such practices has consequences for the role and function of judges. Not all of the urban unit's cases involve procedural mistakes by the agency, but many do. When procedural mistakes occur, judges function as traffic cops, directing the bureaucratic traffic generated by agency processing errors, rather than making evaluative and complex judgments about the underlying disputes.

\section{Exercising Discretion}

As noted above, judges occupy a unique perch. Part welfare system bureaucrat and part judicial officer, they can have characteristics of both. Their professional training and designated role within the bureaucracy provide a different and fresh perspective from which they can scrutinize agency practices and procedures, as well as the decisions that result. But they can also choose not to cast a distinguishing eye, instead exercising their discretion in ways that are aligned with prevailing practices on the front line. Earlier research by this author (Lens 2009, forthcoming) develops typologies of judging; some judges, whom I called bureaucrats, predominantly choose to align themselves with the agency whose decisions they review. They generally act in ways similar to frontline workers, enforcing the norms and practices of the bureaucracy. Thus, they fail to fully scrutinize those practices. On the other end of the spectrum are judges I call adjudicators. ${ }^{6}$ They continually challenge and scrutinize the agency, emphasizing their neutrality and role as a judicial official. This study extends the earlier analysis to closely dissect how judges in each of these categories execute certain judicial tasks and to examine how these different approaches affect the processing of disputes. For purposes of illustration, I choose the cases that provide the most contrast and are most representative of each approach.

In both counties, judges must be law school graduates admitted to the state's bar. They are selected through the state's civil service system and must pass the appropriate civil service exam. They are authorized to preside at hearings by the State Commissioner of Social Services, whom they represent. They come from a wide range of legal backgrounds. Some begin in private practice, others in public interest law, still others in state or local law enforcement. The state makes efforts to recruit individuals who have worked as legal aid attorneys or have experience

6. As the earlier research reveals, judges can be assigned places on a continuum between the adjudicator type and the bureaucratic type. All exhibit the characteristics of each type to some extent. The same judge is capable of acting as an adjudicator in one hearing and as a bureaucrat in another (especially judges in the middle of the continuum), although one approach typically predominates. 
with low-income populations. Prior experience as a judge is not a job requirement; among the 10 judges interviewed, only two had such experience. Of the 17 judges observed in both units, five are female and 12 male. Two of the 17 judges are people of color. Some have served as administrative law judges for many years; others had only a few years' experience.

Judging is a highly skilled and professionalized endeavor. In part, the variability of approaches among judges is possible because of the wide discretion inherent in judging. Although the rules of the adversarial process set the structure for hearings (e.g., requiring coequal participation by the parties), there is ample room for the judge to determine what is heard and how. Specifically, two key tasks shape how a hearing proceeds. First, the judge must decide how the dispute's issues and parameters will be defined. Second, the judge must decide what facts are relevant to the dispute as defined and what evidence is required to prove those facts. Although judges are expected to be impartial and are not expected to play an investigatory role, hearings differ from more formal judicial proceedings in that the regulations permit the judge to assist the appellant in eliciting documents and testimony, especially if the appellant has difficulty questioning a witness. The state regulations also provide that the technical rules of evidence need not apply. Judges thus have more flexibility in presiding over hearings than they have in other sorts of proceedings. The ways in which judges execute these tasks reveal how they perceive themselves in relation to the welfare bureaucracy.

Defining the dispute: process versus substance.-Both frontline and judicial decision making involve applying a specific law or rule to a specific set of facts. However, rule-following has different meanings in administrative and judicial contexts. Within the judicial context, rule-following is a highly skilled endeavor. As one judge put it, "If I don't follow the rules, they can just get someone across the street to do it." It requires a series of analytical and interpretive steps, including identifying the relevant law and interpreting it within the context of specific facts. It also requires recognizing unintended consequences as well as discrepancies between the law as applied and the law's primary purpose. Decisions are fashioned to account for these factors. As Robert Kagan (2010, 171) notes, a judge "looks backwards to preexisting rules (precedents) to discern what they seem to require, but then 'looks forward' to assess the consequences of following an ostensibly applicable rule." Judges then use "judicial creativity" to provide a different interpretation of the rule or to create a new rule (172).

In contrast, rule-following by frontline workers is more routinized and less analytical. They pay little attention to the general purposes underlying the rule. Although some caseworkers may look for ways around the rules if they deem a client deserving (Maynard-Moody and Musheno 2003), the default position, especially within welfare bureaucracies, is 
the rigid, mechanical application of rules within harsh service technologies. A web of formal rules and informal practices requires public assistance recipients to comply with numerous processing demands. For example, they are required to contact the agency at certain junctures or to provide particular documents at specific times (Brodkin and Majmundar 2010). As a consequence, rules are often reduced to process at the expense of substance; for example, a rule that requires participants to contact the agency if they cannot attend a scheduled appointment becomes more important than the overall purpose of the meeting or the substantive reason for missing it.

Judges can choose to replicate and reinforce this approach by focusing on participants' procedural missteps, as the agency defines them, rather than on the substantive dispute underlying such events. The urban unit hearing for Rebecca Jones provides an illustrative example of this approach. ${ }^{7}$ In the Jones case, the agency discontinued the appellant's assistance when she allegedly failed to attend a recertification appointment and to provide verification of her work hours and residence. The appellant's explanation, offered at the beginning of the hearing, was that she was in school on the date and at the time of the appointment. She argued that the agency knew she was in school and that she went back to the agency at a later date to provide the requested documents. The judge ignored this explanation, focusing instead on her alleged failure to contact the agency and explain her absence:

Appellant (AP): Uh, I was in school that whole time and they knew because I . . . I gave them the letter.

Judge $(\mathrm{J})$ : That's all good and well but once they give you an appointment notice they are expecting something from you by that appointment date. When they don't get it they take action against you.

AP: All right.

J: I don't know why you wouldn't pick up the phone to try and contact them: "I'm not going to be able to make it but I'm working on it and I could get it to you by this date." Why wouldn't you do something like that? Why wouldn't you follow through?

AP: When I called they messed it up. They always-the phone keeps ringing, or closes down.

$\mathrm{J}$ : You mean just based on past experiences?

AP: Yes.

J: That's not what happened this time.

AP: It happened this time also. When you call it rings out or just goes-the line goes dead.

[There is a brief deviation from this line of questioning when the judge asks the appellant where she went to school and whether it was part-time or fulltime.]

7. To protect the confidentiality of the judges and the appellants, all names of hearing participants are pseudonyms. 
$\mathrm{J}$ : The . . uh . . a appointment notice . . um [pause] gives you a phone number to call, specifically to your worker, that number.

AP: Right, but he's . . . he's not my worker. So I didn't even see him the next time I came in.

$\mathrm{J}$ : But regardless, that's the number they tell you to contact.

AP: Okay.

J: You know and it's assigned to an aide-a worker or an aide. That's the number they are telling you to contact if you are not able to make the appointment or unable to get the documents by the due date.

By narrowing the issue to whether the appellant called the agency, the judge chose to focus solely on rules of process, not on substance. In essence, she enforced the agency's rules rather than scrutinizing them. Thus, she fails to engage in the complex acts that constitute judging. A more judicial approach would involve considering the agency's application of its rules as well as the appellant's actions. It would consider the purposes of rules on recertification (to prove ongoing eligibility, as the appellant did) as well as whether the agency's practices and procedures interfere with the appellant's ability to comply. Instead of dismissing the appellant's complaints about the agency's phone systems, the judge could have examined how the system might prevent participants from complying with the agency's directive to call if they cannot attend a scheduled appointment. The judge also could explore whether the agency interfered with the goals of welfare law (e.g., to encourage self-sufficiency) by unilaterally scheduling a recertification appointment when the appellant was in school. By doing so, the agency forced the appellant to choose between attending the appointment and attending school.

However, the observations suggest that judges who follow a bureaucratic approach are hesitant to delve into such substantive applications or interpretation of the law. A suburban unit hearing for Danielle Adams provides another illustrative example. Like the preceding case, the Adams case involves a discontinuance of assistance for a failure to attend a recertification appointment and to submit requested documents. The appellant is cognitively impaired and came to the hearing with a case manager for the disabled. In response to the judge's question about why she failed to attend the appointment, the appellant explained that she "sometimes forgets." She said that the notice advising her of the recertification appointment "didn't register" but that she subsequently came in with the requested papers and proved her continuing eligibility. In response, the judge prompted the agency to submit evidence that it properly mailed the notice of appointment. The disabled-services case manager, who is not affiliated with the welfare agency, explained that the appellant has an IQ of 64 . The case manager also testified that she helped the appellant to reschedule the appointment and submit the requested documents when the appellant showed her the appointment 
letter a few days after the scheduled date of the recertification appointment. She also explained that she informed the appellant's welfare caseworker of the appellant's intellectual impairment but that the agency repeatedly denied the appellant assistance. The judge advised the appellant to reapply for benefits, to attend all her appointments, and to submit her documents. After the hearing, and after the appellant and her case manager left the room, the judge explained that he did not have the authority to make a judgment on the appellant's cognitive ability.

The judge's use of discretion suggests that he operates with a very narrow and constricted view of his professional judgment and authority. He chose to ignore the underlying purposes of the law and to define the dispute as the agency did: a dispute about process (whether the agency properly mailed the letter; whether the appellant attended the appointment) rather than about substance (whether the appellant fully understands what she is required to do; whether she is eligible to be recertified). His unwillingness to judge the appellant's cognitive ability reveals a reluctance to exercise his professional skills and make an independent assessment of credibility and fault. Finally, in encouraging the appellant to resolve the dispute by reapplying, the judge suggests that the agency's procedural demands limit his power and fully constrain his authority.

Judges who follow an adjudicator approach exercise their power and authority very differently than bureaucratic judges do. Adjudicators intervene more actively in the dispute before them, remedying instead of replicating the consequences of the agency's heavy reliance on procedural compliance. This is illustrated by the hearings for Michelle Tyler and Robert Morris. Handled by different judges in the suburban unit, these hearings both involve missing documents.

The Morris hearing involved an appeal of a denial of an emergency grant to restore gas and electricity service shut off for nonpayment. The agency denied the appellant's request because he did not submit the required documents. Specifically, he did not submit verification that he was unable to enter into an agreement with the utility company to reduce payments in order to avoid the shutoff. In the Adams hearing, the judge strictly adhered to the agency's procedural demands; in contrast, the judge presiding over the Morris hearing adopted a flexible stance, asking the agency to work it out. The agency agreed to give the appellant additional time to submit the document. The judge also retained her authority over the dispute, suspending the hearing until that afternoon in order to give the appellant time to secure the document. He did, and the dispute was resolved.

The judge in the Tyler hearing also intervened to resolve a dispute regarding missing documents. The agency denied Tyler's request for reimbursement of day care expenses because she failed to submit re- 
quired documents. She claimed that she submitted the documents and "desperately" needed reimbursement. She also indicated that she needed the agency to provide proof of her ongoing child care benefits so that she could continue working. The judge halted the hearing and asked the agency's representative to contact the appellant's welfare caseworker, confirming to the caseworker that the appellant provided the required records. After the representative did so, the judge arranged, through the caseworker, for the appellant to receive agency approval that day for both ongoing and retroactive day care benefits.

In sum, appellants in all four of the described hearings faced a crisis of need, but the judges in the Tyler and Morris hearings reacted very differently than the judges in the Jones and Adams hearings. The judges in the Tyler and Morris proceedings circumvented any procedural irregularity by using their professional discretion and authority to cut through the red tape and resolve the dispute. Their actions reveal a view of the law that is more flexible and expansive than the views held by their counterparts in the Jones and Adams hearings. Part of their role, the observations suggest, is to ensure that the parties meet the goals and purposes underlying the law and regulations. Another part is to ensure that otherwise eligible participants are not denied aid because of agency practices that impose barriers to claiming welfare benefits (Brodkin and Majmundar 2010).

Determining the facts and choosing evidence.-Judges can use their discretion to narrow or expand the set of facts deemed relevant in a dispute. They also decide which sources of proof they will accept as evidence to corroborate these facts. On the front lines, relevant facts and sources of proof are narrowly defined. Agency commands are typically segmented into discrete and specific acts. For example, the agency directs a recipient to attend a work activity on a given date. If the recipient misses an appointment, the agency requires an explanation and corresponding proof of what happened on that day; the backdrop and circumstances of participants' lives are usually deemed irrelevant. Bureaucratic judges often adopt this approach, narrowly limiting the range of relevant facts and relevant proof.

An illustrative example comes from the hearing held in the suburban unit for Amanda Ryan. In this case, the appellant challenged a work sanction. She explained that her child needs continuous care because he has a traumatic brain injury from being struck by a car. She said that she told the agency she can only work when he is in school, and she often leaves work to care for him. She testified that the school was closed on the day she missed her work appointment. As proof, she submitted a letter in which her physician confirmed the child's brain injury and need for 24-hour care. However, the judge deemed a much narrower set of facts and proof to be relevant; he wanted confirmation from the school that it was closed on the day she missed the appointment, and 
the appellant did not have it. The appellant considered the basic facts of her life to be sufficient proof to explain her absence on that day; providing care for a severely injured child requires her constant attention. To the judge, they were not sufficient; his concern fell on the date in question, not the larger events surrounding it.

A similar case from the urban unit also involved a missed appointment. The appellant was pregnant and explained that she received treatment for preeclampsia on the date of the appointment. She testified that she gave birth early, about 2 weeks after her missed appointment, and that her newborn remained in the hospital for 2 weeks after the birth. She produced a doctor's note indicating that she required urgent care during that time period, but the note was dated after the date of the missed work appointment. The judge, like the judge in the Ryan hearing, discounted the appellant's proof, telling her: "The only appointment we really want to focus on at this moment is the April 28 appointment with the city." Also like the judge in the Ryan hearing, he insisted that the only acceptable proof is verification from a third party; in this instance, he required proof that she had a medical appointment on the date in question.

Both judges refused to consider as relevant the facts and circumstances of the appellants' lives (the burdens of caring for a severely disabled child in the first case and the chaos and challenge of a high-risk pregnancy in the second). This narrow focus precluded any consideration of whether the imposition of sanctions in those circumstances was consistent with the overall objectives and goals of the work rules. In essence, both judges forfeited their judicial prerogative to analyze and interpret the relevant rules. They failed to examine whether the rules' underlying purposes and intent were lost in the minutiae and inflexibility of their application. In short, they refused to engage in one of the elementary tasks of judging, which demands more than a rote and rigid application of the rules.

The observations suggest that adjudicators are also confined by the rules regarding sanctions. The rules permit the agency to impose a sanction if a recipient misses a single appointment, no matter what other work activities they engage in. However, adjudicators are more flexible than bureaucratic judges in the proof they require. For example, adjudicators accepted an appellant's testimony as proof of an illness but could require a physician's verification. ${ }^{8}$ They also seek ways to mitigate

8. Documentary proof is helpful in all legal proceedings, including administrative hearings, but it is not required. A judge may exercise discretion in deciding which form of proof (the written or the spoken word) is acceptable in a case. As one judge explained in an interview, "paper talks," but judges are in fact encouraged to rely on the testimony of the appellant. Another judge explained an "unwritten policy" that documentation is not needed to establish an appellant's credibility. One may reasonably conclude that the bureaucratic judges apply a stricter standard of proof than is required. 
the harshness of some of the work rules. During an interview, for example, one judge criticized a law requiring participants to comply with the work rules while they earn a 4-year college degree. He asserted that the law "penalizes people for being in college." He explained that his decisions direct the agency to find a work assignment that is close to the appellant's school or to provide sufficient time between school and the work assignment, so that appellants can get to both. In this way, he is able to align frontline practices with a primary goal of the work rules: to encourage self-sufficiency.

Bureaucratic and adjudicator judges also differ in the extent to which they rely on agency records. Judges who operate under a bureaucratic approach are more likely to rely on agency records as the primary (and sometimes only) source of information used to decide a dispute. As noted above, the hearing system requires that the agency record must first be free of procedural errors and include properly addressed notices and supporting documents. Once this threshold is met, bureaucratic judges are seldom willing to accept arguments that contradict the records. Such judges treat these records as the agency does, considering them to be repositories of the most true and accurate version of the events being contested. Such a perspective makes it difficult for the appellant to contest or contradict the records. If an event is not recorded in the file, the agency and some judges assume that it did not occur. For example, disputes commonly arise over whether appellants submitted requested documents to the agency; appellants often insist that the agency lost the documents, and the agency often insists that it never received the documents. Compared to counterparts who have an adjudicator approach, judges with a bureaucratic bent are less receptive to such testimony. Similarly, if the case file does not include a notation that the appellant called the agency, bureaucratic judges typically disbelieve or ignore the appellant's testimony that he or she called. In short, bureaucratic judges routinely reject testimony about events if the testimony cannot be corroborated through bureaucratic verification.

In contrast, adjudicators are more skeptical of the accuracy of agency records. In an illustrative example from an urban unit hearing, the agency's records indicated that the appellant was working and thus ineligible for assistance. Casting doubt on the veracity of those records, the judge noted that they are only "internal worksheets" and that "it could be somebody else with a similar Social Security number or something." Likewise, such judges are less likely to assume that agency records are complete. In an urban unit hearing for Nancy Miller, the appellant could not produce proof that she went to the agency to make up a work appointment she missed while recovering from illness. The judge did not rebuff her; instead, he acknowledged that the agency often fails to record such contacts, telling her: "They're gonna drop the ball half the 
time, even if you showed up there and [they] forgot to put down: 'Oh, yeah. She was here and I had to turn her away."”

Differences in judges' notions on what constitutes acceptable proof and in their willingness to rely (or not) on agency records mean that different judges may handle the same issues in very different ways. The hearings for Richard Mincy and Paula Masters graphically demonstrate this. Different judges presided over the hearings, but they involved the same issue: whether the appellant was medically able to comply with work rules. In the Mincy hearing from the suburban unit, the judge chose to narrow the acceptable proof to a standard employability form completed by a physician and submitted by the agency. The form indicated that the appellant was employable but had some limitations. It provided minimal information on the appellant's medical condition and used check marks to indicate the appellant's ability to perform a variety of activities (e.g., standing, walking). The appellant attempted to submit additional evidence, both through testimony and more detailed medical reports, that he suffers from several ailments and that the combination of conditions makes it difficult for him to work. The judge rebuffed his proof, telling him, "It's not relevant. What's relevant is whether or not you could work." He continued: "The issue is employability, not what disease you have." The judge further explained: "I'm not a doctor. I can't make a diagnosis."

In contrast, the file in the Masters hearing from the urban unit also included evidence that the appellant was employable with limitations, but the judge treated this evidence as the beginning of the inquiry, not the end. Unlike the judge in the Mincy hearing, the judge in the Masters hearing positioned the appellant as a source of authority for her own medical condition, asking her, "Why do you feel you can't work?" She noted she had one problem, and to insure that he had a complete picture of her many ailments, the judge asked whether she also "ha[d] any other problems?" He methodically elicited both her oral testimony and the evidence from medical records she brought. He occasionally read from the records, which detailed her many aliments, the treatments she received, and the list of her medications.

In the Masters hearing, the judge gave the appellant the space and time she needed to present her version of the facts. In doing so, he fulfilled one of the primary tasks of judging: to elicit testimony and evidence from each side of the dispute so that he can reconcile conflicting facts and make a decision. In the Mincy hearing, the judge did exactly the opposite. She refused to consider any evidence from the appellant. She relied solely on an agency-approved employability form, suggesting that facts are disposable unless they are accepted in the bureaucratic realm. Her refusal to consider the appellant's evidence seemed to indicate that her decision was preordained and the hearing itself a formality. 


\section{Discussion}

Bureaucratic administration and judicial decision making are often at odds with one another. As Jerry Mashaw observes, adjudication "is profoundly anti-bureaucratic" (1992, 1055-56); adjudication emphasizes individualized justice, but bureaucratic administration is concerned with uniformity. The adversarial system is premised on conflict and the legitimacy of opposing views, but administration is premised on the consistent application of one view. Bureaucracies run on hierarchy and centralization; adjudications are decentralized and nonhierarchical. ${ }^{9}$ Adjudication emphasizes the use of discretion; administration deemphasizes it. Bureaucracies that use both bureaucratic and adjudicative types of decision making (most do) are constructed, in essence, to continually reenact the classic conflicts: rules versus discretion, the individual versus the masses, and hierarchy versus decentralization.

These tensions can be beneficial. A decision-making system attuned to the individual can fine-tune laws meant for mass application and prevent unjust or unintended consequences. A surfeit of professional knowledge, discretion, and skill can act as an antidote to an excess of rules and an unskilled workforce. A system that requires participation by appellants, as does the adversarial process, can compensate for their lack of input in decision making on the front lines.

However, any seepage between the two systems must be guarded against if these benefits are to occur. As a threshold requirement, the disputes generated on the front lines must be ripe for resolution by the fair-hearing system. This study's findings suggest that too many agency errors, especially errors of process, can prevent the ultimate resolution of disputes. Instead of providing an opportunity for judges to exercise their professional expertise, the existence of so many procedural errors reduces their role to that of a clerk who processes paperwork and sends it back to the agency. Much like what occurs on the front lines, interactions in the hearings are condensed into exchanges over paperwork and process rather than substance and need. In essence, hearings become indistinct from the bureaucracy, providing only temporary relief while failing to uncover and scrutinize the substantive conflicts underlying disputes.

Maintaining the distinction between the administrative and the judicial, a task that falls within a judge's authority and control, is essential in resolving disputes that are ripe for review. As this study's findings

9. Unlike judges in judicial courts, administrative law judges are supervised. Their decisions are issued in the name of the State Commissioner of Social Services and their supervisor. (A small number of judges issue decisions in their own names.) However, their determinations typically prevail because of the large volume of cases, the professional status of the judge, and the fact that a presiding judge assesses appellants' credibility through personal contact with the parties. 
suggest, judges can take widely divergent paths in exercising their discretion, and these paths have different consequences. Judges with a bureaucratic approach break down the often-fragile wall separating the front lines from the hearing room, and that wall is required if hearings are to function properly. Instead of employing a different form of decision making, they parallel the bureaucracy by focusing on process and the rote application of rules.

Consistent with bureaucratic demands for standardization, judges who operate under a bureaucratic approach apply detailed procedural demands uniformly to all, obscuring or ignoring the capabilities and circumstances of individual clients. The Adams hearing provides a particularly striking example of this. Despite evidence of the appellant's impairment and eligibility for assistance, the judge chose to focus on the narrow question of whether an intellectually impaired appellant submitted requested documents on time, claiming he did not have the authority to assess whether her impairments compromised her ability to do so.

Similarly, judges who follow a bureaucratic approach adhere closely to the rigid and narrow standards that frontline workers employ to assess proof. In this hierarchy of proof, agency records nearly always trump appellants' offers of evidence. Also limited is the range of documents accepted as proof; such judges ask for nothing more or less than the same document required on the front lines. This restrictive view of evidence diminishes other defining features of judicial decision making: the ability to attend to the nuances of language and context, as well as the ability to draw from alternative sources in assessing the coherence and credibility of appellants' explanations.

In contrast, judges who adopt the adjudicator approach use their power and authority to individualize disputes and encourage competing versions. They replace the front line's often-mechanical checklist of documents with a wider range of documents and other types of proof. Their skepticism and scrutiny of agency records creates a space where alternative explanations can emerge. They are more willing than bureaucratic judges to consider the goals and purposes underlying the law and rules, as the judges in the Tyler and Morris hearings did when they cut through the red tape to consider one appellant's eligibility for an emergency utility grant and another's for day-care reimbursement.

This study's evidence can be viewed from a different perspective. One might contend that the bureaucratic judges also consider the goals and purposes underlying welfare reform. Under the 1996 law (110 Stat. 2105), welfare ceases to be an entitlement. These judges give meaning and effect to that provision as well as to the law's emphasis on personal responsibility and self-sufficiency. Adherence to the formalistic demands embedded in regulations and agency practices is characteristic of the legal model of decision making, but it can also be viewed as a way to 
uphold the rule of law (Simon 1983). Arguably, the judge in the Jones case was doing just this when she identified the appellant's alleged failure to call the agency as the linchpin of the case. This perspective suggests that the difference between the approaches of adjudicator and bureaucratic judges is not whether the purposes of the law are considered but which purposes take priority.

However, this study's examples, and particularly the Jones case, suggest that bureaucratic judges do not simply choose between conflicting goals; they eschew consideration of such goals if weighing them requires scrutinizing the agency's practices. In essence, such judges apply a double standard. For example, the judge in the Jones case scrutinized the appellant's behavior for evidence of personal responsibility (whether she contacted the agency) but did not examine agency practices that may discourage the exercise of responsibility (e.g., a poorly designed communication system that may render a recipient's exercise of personal responsibility futile). Of course, an assessment of both appellant actions and agency practices does not mandate a particular outcome; a judge could conclude that the appellant was at fault, or not. But it ensures that the law is applied in an evenhanded way to both the agency and appellants. ${ }^{10}$ It also ensures the preservation of the law's underlying goals.

Common among the bureaucratic judges is the failure to exercise such evenhandedness by scrutinizing the agency's practices, as well as the appellants' actions. In this, they eviscerate the purpose and promise of hearings. The failure renders hearings ineffectual as a check against arbitrary agency action, including actions that may undermine the purposes of the law. Instead of making an independent assessment of what the rules require, bureaucratic judges substitute the agency's view of the rules. This view is often grounded in a form of excess proceduralism. Such actions hinder rather than advance the legal mode of decision making, which requires more than a rote and rigid application of the rules. Potential misapplications of the law remain uncorrected, and goal displacement, the particular plague of welfare bureaucracies (Brodkin 1986), remains unchecked.

Emphasis on due process and the way in which each individual case fits within the purposes of the law can, at times, clash with the efficient and uniform implementation of public policy. The emphasis slows implementation, stressing different values and concerns (Asimow 1999). However, this study suggests that the adjudicators compensate for and correct some of the deficiencies of administration on the front lines.

10. Judges differ over which goals to emphasize, especially in the context of a law that encourages help along with hassle (Mead 2003). But such differences are inevitably a part of any adjudicatory system, and judges often disagree over the interpretation of laws. Such disputes are often resolved through the appeals process, available here in the form of court review of fair-hearing decisions. 
They do so by aligning themselves with the practices and procedures of the adversarial system. Far from impeding public policy, they advance it by replacing the often mechanized judgments of the front lines with an individualized approach that more closely aligns with the purposes of the law. Their close scrutiny enhances the possibility that hearing decisions will affect frontline practices. ${ }^{11}$

The adjudicator's individualized and assertive approach also sometimes lends itself to problem solving. In the Tyler and Morris hearings, the judges used their authority to pressure the agency to resolve the disputes. Arguably, such an approach reveals less a legal than a social work orientation; the judge intervenes in the dispute as a benevolent supervisor on the front lines might. Notably, however, judges in both cases worked within the confines of the law and the procedural demands of the bureaucracy. They did not alter the eligibility rules or the agency's demand for a specific document; in one case, the judge requested only that the appellant be given time to obtain the required document. In another, the judge asked the agency representative to confirm receipt of documents. He then suggested that the agency resolve the matter in the appellant's favor. In short, they asked but did not direct. They facilitated a solution to the dispute in ways not unfamiliar to judges in other legal settings. The solution allowed them to rectify the goal displacement and slippage that often occurs on the front lines. Adjudicator judges, including those who seek to resolve disputes rather than adjudicate them, maintain a distinction between a legal model of decision making and what William Simon (1983) refers to as the social work model. It involves a more flexible and individualized form of decision making than that found in the legal model, which is more directly guided by rules and regulations.

The existence of both adjudicator and bureaucratic approaches in the same system raises an obvious question: why the differences? Variations in style are of course inevitable, especially in positions that involve high levels of skill and discretion (Conley and O'Barr 1990), but the type of variation here is of particular interest; some judges are captured by the bureaucracy and others are not. Choosing an arguably surprising path that reduces their power and authority, bureaucratic judges deemphasize their skills and professional training. The form of rule following that they exhibit is usually less common among managers and elites than among workers with little power. A combination of hierarchy and status insecurity leads workers to rely heavily and mechanically on rules rather than exercising an individualized style of decision making (Mer-

11. Empirical evidence is lacking on whether hearing decisions can reform frontline practices, although research assumes that they do not (see Super 2005). One could imagine that such reforms might happen if the agency continually loses hearings because it schedules appellants' appointments at inconvenient times or fails to improve its communication systems. 
ton 1940; Herzfeld 1993; Oberfield 2010). Moreover, unlike frontline workers, judges face little risk from exercising discretion in complex ways. Judges may use discretion without making interpretive judgments about appellants' moral worth (Maynard-Moody and Musheno 2003). The proper use of discretion involves following their professional training as well as the principles and practices that guide adversarial proceedings.

Many factors shape an individual's behavior within an organization (Saks and Ashforth 1997). Judges in this study received similar training and supervision. They operate in the same organizational environment under the same laws and regulatory structure. It is thus noteworthy that they follow different approaches. This suggests that several factors, not just organizational environment, influence the ways in which the judges choose to exercise their discretion. This study does not find that gender or ethnicity links to discernible patterns in the style of judging. Larger sample sizes and a different methodological approach are needed to determine the effects of such characteristics. Further research is also needed to identify other factors.

The bureaucratic approach to judging also serves as a cautionary tale. One view is that a more professionalized work force is the answer to what ails bureaucracies, and particularly welfare bureaucracies. Professional judgment and discretion, the argument goes, will produce reasonable and rational decisions that are closely aligned with the purposes of the law (Adler 2010; Kagan 2010). This study suggests, however, that the mere existence of professionals is insufficient to achieve such outcomes; even highly skilled professionals who hold positions of relative power within the bureaucratic hierarchy will choose not to exercise that power.

\section{Note}

Vicki Lens is an associate professor at the Columbia University School of Social Work. Her primary research interest is in sociolegal studies, where she uses ethnographic and other methods to study legal settings, among them the welfare fair-hearing system and family court. She has also conducted several studies on the implementation of work sanctions under welfare reform. She can be reached at v12012@columbia.edu. This study was supported by a grant (0849193) from the National Science Foundation, Law and Social Science Program.

\section{References}

Adler, Michael. 2003. "A Socio-Legal Approach to Administrative Justice." Law and Policy 25 (4): 323-52.

$\rightarrow-$ 2006. "Fairness in Context." Journal of Law and Society 33 (4): 615-38.

. 2010. "Understanding and Analysing Administrative Justice." 129-60 in Administrative Justice in Context, edited by Michael Adler. Oxford: Hart. 
Asimow, Michael. 1999. "The Administrative Judiciary: ALJs in Historical Perspective." Journal of the National Association of Administrative Law Judges 19 (2): 25-33.

Bernard, Phyllis E. 2003. "The Administrative Law Judge as a Bridge between Law and Culture." Journal of the National Association of Administrative Law Judges 23 (1): 1-55.

Brodkin, Evelyn Z. 1986. The False Promise of Administrative Reform: Implementing Quality Control in Welfare. Philadelphia: Temple University Press.

$\rightarrow-$. 1997. "Inside the Welfare Contract: Discretion and Accountability in State Welfare Administration.” Social Service Review 71 (1): 1-33.

Brodkin, Evelyn Z., and Malay Majmundar. 2010. "Administrative Exclusion: Organizations and the Hidden Costs of Welfare Claiming." Journal of Public Administration Research and Theory 20 (4): 827-48.

Brodoff, Lisa. 2008. "Lifting Burdens: Proof, Social Justice, and Public Assistance Administrative Hearings." New York University Review of Law and Social Change 32 (2): 13189.

$\rightarrow$ Casper, Jonathan D., Tom R. Tyler, and Bonnie Fisher. 1988. "Procedural Justice in Felony Cases." Law and Society Review 22 (3): 483-508.

Charmaz, Kathy. 2006. Constructing Grounded Theory: A Practical Guide through Qualitative Analysis. Thousand Oaks, CA: Sage.

Conley, John M., and William M. O’Barr. 1990. Rules versus Relationships: The Ethnography of Legal Discourse. Chicago: University of Chicago Press.

Creswell, John W. 2007. Qualitative Inquiry and Research Design: Choosing among Five Approaches. 2nd ed. Thousand Oaks, CA: Sage.

Emerson, Robert M., Rachel I. Fretz, and Linda L. Shaw. 1995. Writing Ethnographic Fieldnotes. Chicago: University of Chicago Press.

$\rightarrow$ Fording, Richard C., Joe Soss, and Sanford F. Schram. 2007. "Devolution, Discretion, and the Effect of Local Political Values on TANF Sanctioning." Social Service Review 81 (2): 285-316.

Handler, Joel F. 1986. The Conditions of Discretion: Autonomy, Community, Bureaucracy. New York: Sage.

- 1996. Down from Bureaucracy: The Ambiguity of Privatization and Empowerment. Princeton, NJ: Princeton University Press.

$\rightarrow$ Hasenfeld, Yeheskel. 2000. "Organizational Forms as Moral Practices: The Case of Welfare Departments.” Social Service Review 74 (3): 329-51.

Herzfeld, Michael. 1993. The Social Production of Indifference: Exploring the Symbolic Roots of Western Bureaucracy. Chicago: University of Chicago Press.

Kagan, Robert A. 2010. "The Organisation of Administrative Justice Systems: The Role of Political Mistrust.” 161-82 in Administrative Justice in Context, edited by Michael Adler. Oxford: Hart.

Knoblauch, Hubert. 2005. "Focused Ethnography." Forum: Qualitative Social Research 6 (3), article 4.

Lens, Vicki. 2009. "Confronting Government after Welfare Reform: Moralists, Reformers, and Narratives of (Ir)Responsibility at Administrative Fair Hearings." Law and Society Review 43 (3): 563-92.

- Forthcoming. "Administrative Justice in Public Welfare Bureaucracies." In Work and the Welfare State: The Making of Workfare and Active Labor Market Reforms from Public Policy to Street-Level Practice, edited by Evelyn Z. Brodkin and Gregory Marston. Washington, DC: Georgetown University Press.

Lipsky, Michael. 1980. Street-Level Bureaucracy: Dilemmas of the Individual in Public Services.

$\rightarrow \quad$ New York: Sage. view 58 (1): 3-27.

Lurie, Irene. 2006. At the Front Lines of the Welfare System: A Perspective on the Decline in Welfare Caseloads. Albany, NY: Rockefeller Institute Press.

Mashaw, Jerry L. 1983. Bureaucratic Justice: Managing Social Security Disability Claims. New Haven, CT: Yale University Press.

- 1992. "Organizing Adjudication: Reflections of the Prospect for Artisans in the Age of Robots." UCLA Law Review 39 (5): 1055-65.

Maynard-Moody, Steven, and Michael Musheno. 2003. Cops, Teachers, Counselors: Stories from the Front Lines of Public Service. Ann Arbor: University of Michigan Press. 
Mead, Lawrence M. 2003. "The Primacy of Institutions." Journal of Policy Analysis and Management 22 (4): 577-80.

Merton, Robert K. 1940. "Bureaucratic Structure and Personality." Social Forces 18 (4): 560 68.

$\rightarrow$ Meyers, Marcia K., Bonnie Glaser, and Karin MacDonald. 1998. "On the Front Lines of Welfare Delivery: Are Workers Implementing Policy Reforms?” Journal of Policy Analysis and Management 17 (1): 1-22.

Oberfield, Zachary W. 2010. "Rule Following and Discretion at Government's Frontlines: Continuity and Change during Organizational Socialization." Journal of Public Administration Research and Theory 20 (4): 735-55.

Saks, Alan M., and Blake E. Ashforth. 1997. "Organizational Socialization: Making Sense of the Past and Present as a Prologue for the Future." Journal of Vocational Behavior 51 (2): 234-79.

Sandfort, Jodi R. 2000. "Moving beyond Discretion and Outcomes: Examining Public Management from the Front Lines of the Welfare System." Journal of Public Administration and Theory 10 (4): 729-56.

$\rightarrow$ Simon, William H. 1983. "Legality, Bureaucracy, and Class in the Welfare System." Yale Law Journal 92 (7): 1198-269.

Sunshine, Jason, and Tom R. Tyler. 2003. "The Role of Procedural Justice and Legitimacy in Shaping Public Support for Policing." Law and Society Review 37 (3): 513-48.

Super, David A. 2005. "Are Rights Efficient? Challenging the Managerial Critique of Individual Rights." California Law Review 93 (4): 1051-154.

Tyler, Tom R. 2006. Why People Obey the Law. Princeton, NJ: Princeton University Press. 